\title{
O CONSUMIDOR NA ÓTICA JURÍDICA
}

Bruno Coelho Gonçalves, Juliane Nagafugi de Souza Costa, Ana Augusta Rodrigues Westin Ebaid, Eder Canziane

Universidade do Oeste Paulista - UNOESTE. Curso de Direito, Presidente Prudente - SP. E-mail: anaaugusta@unoeste.br

\section{RESUMO}

Devido às diversas transformações operadas na sociedade, a Constituição federal de 1988, incorporou em suas normas a proteção do consumidor, consubstanciada no artigo 5ㅇ, inciso XXXII "O Estado promoverá, na forma da lei, a defesa do consumidor". Desta garantia constitucional, originou-se o "Código de Defesa do Consumidor", Lei no 8.078, de 11 de setembro de 1990, objetivando estabelecer uma relação de equilíbrio entre consumidores e fornecedores. Este código reconheceu a vulnerabilidade e hipossuficiência, do consumidor, colocando ao seu dispor institutos e instrumentos que lhe garantem as efetivas e integrais prevenção e reparação dos danos que lhe tenham sido causados pelo fornecedor de produtos ou serviços. Este código constituiu um poderoso instrumento de ordem legal que também repercutiu na ordem econômica, disciplinando a coerência dos agentes nas relações de consumo. Assim, o presente trabalho busca analisar a efetividade do Código de Defesa do Consumidor, sob uma perspectiva econômica, abordando seu aspecto de eficiência nas relações de consumo. Eis algumas das facetas do presente trabalho, que visa promover um estudo vislumbrando o critério de eficiência econômica frente às garantias do consumidor.

Palavras-chave: consumidor; código; defesa; garantias; econômica.

\section{THE CONSUMER IN THE LEGAL PERSPECTIVE}

\begin{abstract}
Due to various transformations wrought in society, the federal constitution of 1988 , incorporated in their consumer protection standards as set out in Article 5, paragraph XXXII "The State shall promote, to the law, consumer protection". This constitutional guarantee, originated the "Code of Consumer Protection", Law No. 8,078, of September 11, 1990, aiming to establish a balanced relationship between consumers and suppliers. This code recognized the vulnerability and hipossuficiência, consumer, putting at their disposal institutes and instruments that guarantee the effective and comprehensive prevention and repair of damage to it caused by the supplier of goods or services. This code was a powerful instrument of a legal nature which also reflected in the economic order, disciplining the consistency of agents in consumer relations. Thus, the present study analyzed the effectiveness of the Code of Consumer Protection, from an economic perspective, addressing its aspect of efficiency in consumer relations. Here are some of the facets of this work, which aims to promote a study glimpsing the criterion of economic efficiency in the face of the consumer guarantees.
\end{abstract}

Keywords: consumer; code; protection; garantees; econimic 


\section{INTRODUÇÃO E OBJETIVOS}

A Constituição Federal de 05 de outubro de 1988 trouxe a previsão de proteção ao consumidor. Antes disso não havia qualquer proteção a ele no ordenamento. Desse modo, a pessoa que adquirisse qualquer produto ou prestação de serviço que apresentasse problema ou defeito, estaria subordinada a liberalidade do fornecedor em relação à troca do produto ou reexecução do serviço.

Para mudar essa relação, a Carta Magna previu em seu texto várias considerações relativas ao consumidor:

Constituição Federal

Art. 5.ㅇ…]

XXXII - o Estado promoverá na forma da lei, a defesa do consumidor.

$[\ldots]$

Art. 170. A ordem econômica, fundada na valorização do trabalho humano e na livre

iniciativa, tem por fim assegurar a todos existência digna, conforme os ditames da justiça social, observados os seguintes princípios:

$[\ldots]$

$\mathrm{V}$ - defesa do consumidor;

Atos das Disposições Constitucionais Transitórias

Art. 48. O Congresso Nacional, dentro de cento e vinte dias da promulgação da Constituição, elaborará código de defesa do consumidor.

Observa-se assim que para proteger a fragilidade do consumidor na relação de consumo, o legislador constitucional determinou a criação do Código de Defesa do Consumidor.

Conforme expresso no artigo 4으 do Código de Defesa do Consumidor, ao constituir este o Estado se compromete a atender as necessidades, primando pela dignidade, saúde e segurança do consumidor; e também se propõe a proteger os interesses econômicos, sua qualidade de vida e a relação de consumo. Para tanto, enumera nos incisos princípios através dos quais realizará a Política Nacional das Relações de Consumo. Por exemplo, o inciso I expressa a vulnerabilidade do consumidor, ou seja, sua menor proteção na relação de consumo; já o inciso $\mathrm{V}$ trata de um incentivo aos fornecedores para a criação de um controle de qualidade e segurança de produtos e serviços.

Portanto, as relações entre fornecedores e consumidores estão bem regularizadas no nosso ordenamento jurídico, principalmente por meio do Código de Defesa do Consumidor.

É importante destacar que vivemos em sociedade e devemos observar os bons modos de vivência, evitando ao máximo a criação de atritos com os que estão a nossa volta, priorizando uma convivência harmônica e humanística. Somente quando não há mais outra forma de resolução das 
problemáticas existentes em nosso dia a dia, devemos procurar o Direito, para fazer valer a Justiça, no qual é meio essencial na boa relação entre os seres humanos.

O foco deste trabalho se concentra no Código de Defesa do Consumidor, contribuindo com o olhar jurídico a partir da Constituição Federal. Verifica-se que muitos são os elementos que concorrem para a proteção do consumidor. Compreendendo estes aspectos, objetiva-se desenvolver um estudo no intuito de examinar alguns dos seus principais elementos, especificamente no que tange o Código de Defesa do Consumidor, levando em consideração o contexto econômico.

A partir disso nos remetemos à seguinte questão: A proteção do Estado através do Código de Defesa do Consumidor favoreceu a ordem econômica? Ou seja, após a promulgação de tal Lei, com a prevista proteção à relação de consumo e sob a perspectiva econômica, obtivemos avanços na economia?

\section{O CÓDIGO DE DEFESA DO CONSUMIDOR}

Inicialmente devemos ter a noção de que o Código de Defesa do Consumidor foi editado em 11 de setembro de 1990, ou seja, anteriormente a isso se aplicava nas relações de consumo o Código Civil. Em comparação feita com os Estados Unidos percebe-se um grande atraso na defesa do consumidor no Brasil, pois naquele a proteção havia começado em 1890, com a Lei Shermann, que é a Lei Antitruste americana.

Contudo, devido a tal atraso o Código de Defesa do Consumidor obteve resultados positivos, pois os legisladores trouxeram para o ordenamento brasileiro aquilo que existia de mais moderno quanto à defesa do consumidor.

Entretanto, para melhor vislumbrarmos a diferença entre o período em que a relação de consumo foi regida pelo Código Civil e o que ocorre na atualidade, analisemos um pouco de história. Após a Revolução Industrial houve aumento da população, da demanda e a possibilidade de aumento da oferta. Desse modo, a indústria passou a querer produzir mais, criando a chamada "produção em série".

A partir disso surgiu a sociedade de massa, em que uma das principais características era que a produção somente era planejada pelo produtor, ou seja, o produtor decide fazer uma larga oferta de produtos e serviços para serem adquiridos pelo maior número possível de pessoas. Ou seja, ao fabricar umageladeira, pensava-se em uma, e desta se reproduziam milhares.

Observe-se que em uma relação de consumo deve existir um contrato específico, porém nesse caso o contrato possuía as mesmas características da produção, milhares dele eram 
reproduzidos. Isso porque se supõe que aquele que produz um produto ou serviço de massa planeja um contrato de massa, que passou a ser chamado Contrato de Adesão, e a primeira lei a tratar do assunto no Brasil foi o Código de Defesa do Consumidor. Tal contrato recebe esse nome porque a ele o consumidor só pode aderir, não há discussão, as formas são pré-fixadas.

Esse foi o modelo de produção e oferta de produtos e serviços desde o século XX, mas até 10 de março de 1991 nós utilizados o Código Civil para regular as relações de consumo. Consequentemente até hoje nos baseamos neste Código.Por exemplo, com relação aos contratos sempre pensamos em "pacta sunt servanda", posto que no direito civil assim é.Masnas relações de consumo isso não ocorre, porque, conforme colocado pelo autor Rizzato Nunes, "o consumidor não senta à mesa para negociar as cláusulas contratuais. Na verdade o consumidor vai ao mercado e recebe produtos e serviços postos e ofertados segundo os regramentos que agora o Código de Defesa do Consumidor pretende controlar".

O fato é que nos últimos anos cresceu entre os brasileiros o poder aquisitivo, fator este que levou a população a ter um maior poderio para fazer compras e adquirir bens e serviços. Desde o fim do século passado, de acordo com dados publicados pelo Banco Central, logo após a implantação do Plano Real, o consumo aumentou em todas as categorias de produtos, principalmente nos bens de consumo duráveis. O aumento de consumo decorreu da grande expansão do crédito pessoal, eliminação da ilusão monetária e acréscimo do salário. Um estudo feito por Mattoso e Baltar (1997, p. 294-314) indicou que o aumento do salário mínimo, logo no começo do Plano Real, combinado com o rápido declínio da inflação e o aquecimento do nível de atividades econômicas, permitiu o crescimento no rendimento de 30\% entre 1994 e 1996.

Com o passar dos anos este quadro foi se firmando no cenário nacional, verificando até nossos dias o crescente número do consumo das pessoas.

Tal retrato se molda no aumento da oferta de crédito que a população obteve durante esses anos. E o crédito é um importante propulsor do crescimento da economia. Crédito é uma palavra derivada do latim creditum, que expressa confiança, segurança, acreditar em algo, ou alguém. $\mathrm{O}$ crédito, sob a ótica financeira, significa dispor a um tomador, recursos financeiros para fazer frente a despesas ou investimentos, financiar a compra de bens, etc.

O aumento do volume de crédito aquece a demanda no mercado interno, atuando diretamente e de forma positiva no desempenho do Produto Interno Bruto, que é a soma de todos os bens e serviços produzidos no país. Ao fomentar o consumo, o crédito obriga o setor produtivo a fabricar mais bens e, por consequência, empregar mais pessoas, aumentando a renda da população, melhorando seu nível de vida e seu poder aquisitivo.Percebe-se então que o 
crescimento da economia tem como um dos principais fatores o aumento de crédito entre a população.

O Código de Defesa do Consumidor vem aí estreitar as relações entre consumidor e fornecedor, propondo soluções aos problemas decorrentes de tais relações, contribuindo por auxiliar numa melhor relação entre as partes, evitando abusos, mensurando direitos e deveres para uma relação consumerista mais segura e agradável.

O consumidor quando se sente mais seguro para consumir, acaba por assim fazê-lo e desencadeia todo um processo produtivo que aquece a atividade mercantil de nosso país, favorecendo um crescimento orgânico da economia.

\section{CONCLUSÃO}

Mesmo sendo o Código de Defesa de Consumidor um grande meio que o consumidor possui para requerer seus direitos, a população brasileira ainda pouco o utiliza. Em outras palavras, o brasileiro conhece seus direitos como consumidores, mas pouco os exerce de fato.

Uma pesquisa realizada pela Fundação Getúlio Vargas, em várias cidades brasileiras, revelou que cerca de $82 \%$ das pessoas declaram conhecer seus direitos, ou têm alguma familiaridade com tais dispositivos protecionistas, e 72\% declaram ainda conhecer o Código de Defesa do Consumidor.

Diante destes números expressivos ao reconhecimento de seus direitos, poucos são ainda os que realmente o exercem, uma vez que a Justiça é inerte e esta deve ser acionada pela parte prejudicada em uma lide.

Os principais argumentos levantados na referente pesquisa acima sobre a não busca pela defesa nas relações consumeristas são que "não compensa", ou que "demora muito", ou até mesmo "porque tem vergonha".

É importante destacar que o Código de Defesa do Consumidor está presente na sociedade brasileira, dispondo a toda a população subsídios para requerem seus direitos, que devem ser pleiteados sem receio pelos consumidores que se sentirem prejudicados, zelando assim por construir uma economia mais justa e igualitária, num país que se encontra em um intenso processo de desenvolvimento.

\section{REFERÊNCIAS}

ALMEIDA, João Batista de. Manual de Direito do Consumidor. 5a edição, 2011. São Paulo, Editora Saraiva. 
DONATO, A. Z. Proteção ao consumidor: Conceito e Extensão. São Paulo. Editora Revista dos Tribunais, 1993.

FREITAS, Marcos Lúcio Dóro de. Tudo o que você precisa saber sobre o Código de Defesa do Consumidor. 1a Edição. Editora Letras Jurídicas, 2011.

FUNDAÇÃO GETÚlIO VARGAS. DIRETÓRIO. Apresenta Código de Defesa do Consumidor. Disponível em: <http://direitorio.fgv.br/sites/direitorio.fgv.br/files/pesquisaCDCCJUS.pdf>. Acesso em: 29 de maio de 2014.

GARCIA, Leonardo de Medeiros. Direito do Consumidor: Código Comentado e Jurisprudência. 9ạ Edição. Editora Juspodivm, 2013.

LÚCIO, Wandeck de Brito Gomes. Descomplicando o Código de Defesa do Consumidor: Explicações claras e objetivas. 1aㅡ Edição. Editora Best SellerLtda, 2011.

MATTOSO, J; Baltar, P. Estrutura econômica e emprego no Brasil: a experiência recente. In: REIS VELOSO, J. (Org.). Brasil: Desafios de um país em transformação. Rio de Janeiro: J. Olímpio, 1997, p. 294-314.

NUNES, Rizatto. Curso de Direito do Consumidor. 7ạ Edição, 2012, p. 45.

PINHEIRO, J. S. O Conceito Jurídico de Consumidor, in Problemas de Direito Civil-Constitucional. São Paulo: Editora Renovar, 2000.

SERASA EXPERIAN. Apresenta Painel Econômico.Disponível em:<http://serasaexperian.com.br/livros/4painel/econômico/13.htm>. Acesso em: 12 de abril de 2014.

VASCONCELLOS, Marco Antonio Sandoval; MANUEL, Enrique Garcia. Fundamentos de Economia. 4a Edicção. São Paulo: Editora Saraiva, 2012.

VASCONCELLOS, Marco Antonio Sandoval; PINHO, Diva Bevenides; JUNIOR, RudineiToneto. Introdução à Economia. 1a Edição. Editora Saraiva, 2012.

VASCONCELLOS, Marco Antonio Sandoval; PINHO, Diva Bevenides. 6ạ Edição. Editora Saraiva, 2011 